\title{
ENERGY BALANCE MODEL FOR NATURAL VENTILATION OF GREENHOUSES
}

\author{
Ahmed M. Abdel-Ghany \\ Mechanical Power Engineering Department, High Institute of Energy, \\ South Valley University, Aswan, Egypt
}

(Received July 2, 2006 Accepted January 9, 2007)

Energy balance methods currently used to estimate the natural ventilation rate of greenhouses $\left(\dot{m}_{\mathrm{a}}\right)$ assume that the input energy to the greenhouse is the transmitted solar radiation. An average value for the cover transmittance $\left(\tau_{\mathrm{c}}\right)$ is usually used to estimate this energy. However, this estimate includes a large error due to the spatial variation of $\tau_{\mathrm{c}}$ in the greenhouse. These methods also give negative values of $\dot{m}_{\mathrm{a}}$ at low solar radiation levels (e.g. in the morning and afternoon).

The purpose of this study was to develop a simplified energy balance model to estimate the value of $\dot{m}_{\mathrm{a}}$ precisely. In this model, all modes of energy were treated at the outer surface of the cover to avoid the error caused by using an average value of $\tau_{\mathrm{c}}$. Required environmental parameters to be used in the model were measured inside and outside a single-span glass-covered greenhouse with a floor area of $26 \mathrm{~m}^{2}$ located in the Tokyo area, Japan during four sunny days (Sept. 29 to Oct. 2., 2005) The greenhouse was naturally ventilated using two roof ventilators $(0.6 \mathrm{~m} \times 5 \mathrm{~m})$. Diurnal variations of $\dot{m}_{\mathrm{a}}$ were estimated and compared with the results of other models and showed the necessity of applying the present model. The estimated value of $\dot{m}_{\mathrm{a}}$ was in the range between 0.11 $\mathrm{kg} \mathrm{s}^{-1}$ and $2.25 \mathrm{~kg} \mathrm{~s}^{-1}$ and these results were in accordance with those measured and reported in the literature. The results also confirmed that outside wind at a speed less than $2.5 \mathrm{~m} \mathrm{~s}^{-1}$ has no significant effect on the value of $\dot{m}_{\mathrm{a}}$ and the value of $\dot{m}_{\mathrm{a}}$ resulting from the greenhouse thermal balance depends mainly on temperature difference of air between inside and outside the greenhouse ( $\Delta T$ ). A linear correlation between $\dot{m}_{\mathrm{a}}$ and $\Delta T$ was provided that can be used to estimate the required ventilation rate to maintain the air temperature in the greenhouse at a desired level.

KEYWORDS: Greenhouse, Natural ventilation, Energy balance 


\section{NOMENCLATURES}

\section{Alphabetic symbols}

$A_{c}$ : surface area of the greenhouse cover $\left(\mathrm{m}^{2}\right)$

$A_{\mathrm{f}}$ : surface area of the greenhouse floor $\left(\mathrm{m}^{2}\right)$

$C_{\mathrm{d}}$ : discharge coefficient of the vent (-)

$C_{\mathrm{pa}}$ : specific heat of air at constant pressure $\left(\mathrm{J} \mathrm{kg}^{-1}{ }^{\circ} \mathrm{C}^{-1}\right)$

$C_{\mathrm{w}}$ : wind effect coefficient (-)

$d$ : greenhouse cover thickness (m)

$F_{\text {f-j: }}$ view factor from the floor surface to the surface $j(-)$

$F_{j-\text { : }}$ : view factor from the surface $j$ to the floor surface (-)

$f_{\mathrm{d}}$ : ratio of diffuse to global (direct + diffuse) solar radiation (-)

$g$ : acceleration of gravity $\left(\mathrm{m} \mathrm{s}^{-2}\right)$

$H$ : vertical height of the vent opening (cord joining the two extremities of the vent when it is open and close) (m)

$h_{\mathrm{c}-\mathrm{o}}$ : convective heat transfer coefficient between the cover surface and the outside ambient air $\left(\mathrm{W} \mathrm{m}^{-2}{ }^{\circ} \mathrm{C}^{-1}\right)$

$I_{\mathrm{i}}$ : specific enthalpy of moist air inside the greenhouse $\left(\mathrm{J} \mathrm{kg}^{-1}\right)$

$I_{0}$ : specific enthalpy of moist air outside the greenhouse $\left(\mathrm{J} \mathrm{kg}^{-1}\right)$

$j$ : surface number of the greenhouse cover $(1,2, \ldots, 6)$

$k_{\mathrm{f}}$ : equivalent thermal conductivity of the greenhouse soil $\left(\mathrm{W} \mathrm{m}^{-1}{ }^{\circ} \mathrm{C}^{-1}\right)$

$L$ : vent length $(\mathrm{m})$

$\ell$ : vent width $(\mathrm{m})$

$\dot{m}_{a}$ : ventilation rate $\left(\mathrm{kg} \mathrm{s}^{-1}\right)$

$N_{\mathrm{a}}$ : number of air exchange per hour $\left(\mathrm{h}^{-1}\right)$

$N_{\mathrm{v}}$ : number of ventilators

$n$ : refractive index of the cover material (-)

$Q_{\text {c-o }}$ : convection heat rate between the cover surface and outside ambient (W)

$q_{\mathrm{o}}$ : heat rate conducted into the greenhouse soil surface (W)

$R_{\mathrm{n}}$ : net thermal radiation exchange between the outer surface of the cover and sky (W)

$r_{\mathrm{b}}$ : ratio of beam irradiance received by a tilted surface to that received by a horizontal surface (-)

$r^{2}:$ coefficient of determination

$S_{\mathrm{i}}$ : global solar radiation flux transmitted into the greenhouse $\left(\mathrm{W} \mathrm{m}^{-2}\right)$

$S_{\mathrm{n}}$ : net global solar energy crossing the control volume of the greenhouse (W)

$S_{0}$ : global solar radiation flux at the greenhouse outer surface $\left(\mathrm{W} \mathrm{m}^{-2}\right)$

$T_{\mathrm{c}}$ : cover outer surface temperature $\left({ }^{\circ} \mathrm{C}\right)$

$T_{\mathrm{di}}$ : dry bulb temperature inside the greenhouse $\left({ }^{\circ} \mathrm{C}\right)$

$T_{\mathrm{do}}$ : dry bulb temperature outside the greenhouse $\left({ }^{\circ} \mathrm{C}\right)$

$T_{\mathrm{f}}$ : floor surface temperature $\left({ }^{\circ} \mathrm{C}\right)$

$T_{\text {sky: }}$ equivalent temperature of sky $\left({ }^{\circ} \mathrm{C}\right)$

$T_{\text {wi: }}$ : wet bulb temperature inside the greenhouse $\left({ }^{\circ} \mathrm{C}\right)$

$T_{\text {wo }}$ : wet bulb temperature outside the greenhouse $\left({ }^{\circ} \mathrm{C}\right)$

$U$ : overall heat loss coefficient of the greenhouse cover $\left(\mathrm{W} \mathrm{m}^{-2}{ }^{\circ} \mathrm{C}^{-1}\right)$ 
$V:$ wind speed outside the greenhouse $\left(\mathrm{m} \mathrm{s}^{-1}\right)$

$V_{\mathrm{g}}$ : volume of the greenhouse air $\left(\mathrm{m}^{3}\right)$

$Z$ : vertical depth under the greenhouse measured from the soil surface (m)

Greek symbols

$\alpha_{\mathrm{c}}$ : net absorptance of the cover to global solar radiation (-)

$\beta$ : slope angle of the cover surface (degree)

$\gamma_{\mathrm{s}}$ : surface azimuth angle (degree)

$\Delta I$ : specific enthalpy difference between inside and outside the greenhouse $\left(\mathrm{J} \mathrm{kg}^{-1}\right)$

$\Delta T$ : temperature difference between inside and outside the greenhouse $\left({ }^{\circ} \mathrm{C}\right)$

$\delta$ : evaporation efficiency (-)

$\xi_{j}$ : fraction of the transmitted solar radiation from the surface $j$ that transmitted

back to outside the greenhouse (-)

$\eta$ : solar radiation heating efficiency (-)

$\theta$ : incidence angle of direct solar radiation (degree)

$\theta_{\mathrm{r}}$ : angle of refraction (degree)

$\theta_{\mathrm{z}}$ : solar zenith angle (degree)

$\kappa$ : absorption coefficient of the cover material $\left(\mathrm{m}^{-1}\right)$

$\rho_{\mathrm{a}}:$ density of moist air $\left(\mathrm{kg} \mathrm{m}^{-3}\right)$

$\rho_{\mathrm{c}, j}$ : net directional reflectance of the cover surface $j$ to direct solar radiation (-)

$\bar{\rho}_{\mathrm{c}, j}$ : net directional reflectance of the cover surface $j$ to global solar radiation (-)

$\hat{\rho}:$ interface reflectance on the cover surface (-)

$\rho_{\mathrm{f}}$ : net reflectance of the floor surface to global solar radiation (-)

$\tau_{\mathrm{c}}$ : average transmittance of the greenhouse cover to global solar radiation (-)

$\tau_{\mathrm{c}, j}$ : net directional transmittance of the cover surface $j$ to direct solar radiation (-)

$\bar{\tau}_{c, j}$ : net directional transmittance of the cover surface $j$ to global solar radiation (-)

$\hat{\tau}$ : ransmittance due to absorption of solar radiation through the cover thickness (-)

$\phi$ : opening angle of vent (degree)

$\omega$ : absolute humidity ( $\mathrm{kg}$ of water vapor/ $\mathrm{kg}$ of dry air)

\section{INTRODUCTION}

Ventilation of greenhouses plays a major role in providing a suitable environment for plant growth. In summer, ventilation is for cooling the greenhouse air, and in winter ventilation can remove excess humidity from the greenhouse. Recently, most greenhouse ventilation studies have been focusing on the use of natural ventilation to reduce electric energy consumption by greenhouses. Although investigation of natural ventilation rate in the greenhouses started in the mid 1950s, there is still no adequate method to precisely predict the amount of natural ventilation. Based on the survey of the previous researches performed in this area, the main methods that have been used 
to estimate the natural ventilation rate of greenhouses and the problems associated with each method can be summarized as follows:

(i) Measuring methods (i.e. dynamic tracer gas methods): In such methods, a tracer gas such as $\mathrm{N}_{2} \mathrm{O}$ or $\mathrm{CO}_{2}$ is injected in the greenhouse and the decay rate of the gas concentration is measured [1- 4]. These methods can measure the ventilation rates during the time of experiments only. However, the ventilation rate changes from time to time according to the environmental conditions. Therefore, developing theoretical models to estimate the ventilation rate is necessary.

(ii) Air dynamic models: In such models, ventilation was assumed to be driven by two forces, namely, the wind force and the buoyancy force. The most popular model including these driving forces which is widely used for greenhouses with roof vents, is given by [5] as:

$\dot{m}_{\mathrm{a}}=N_{\mathrm{v}} \frac{A_{e}}{2} \rho_{\mathrm{a}} C_{\mathrm{d}}\left[\left(\frac{g \times H \times \Delta T}{2 T_{\mathrm{do}}}\right)+C_{\mathrm{w}} V^{2}\right]^{0.5}$

Here $\dot{m}_{\mathrm{a}}$ is the ventilation rate of air in $\mathrm{kg} \mathrm{s}^{-1} ; A_{e}$ is the effective opening area of the vent (i.e., $A_{\mathrm{e}}=2 L \times \ell \times \sin \phi / 2, L$ is the vent length, $\ell$ is the vent width and $\phi$ is the vent opening angle in degree); $\rho_{\mathrm{a}}$ is the air density in $\mathrm{kg} \mathrm{m}^{-3} ; g$ is the acceleration of gravity in $\mathrm{m} \mathrm{s}^{-2} ; H$ is the vertical height of the opening in meter; $V$ is the wind speed measured at $4 \mathrm{~m}$ above the ground level outside the greenhouse in $\mathrm{m} \mathrm{s}^{-1} ; \Delta T$ is the air dry bulb temperature difference between inside and outside $\left(T_{\mathrm{di}}-T_{\mathrm{do}}\right) ; T_{\mathrm{do}}$ is the outside dry bulb temperature in degree Kelvin and $N_{\mathrm{v}}$ is the number of roof vents. Value of $\dot{m}_{\mathrm{a}}$ from Eq. (1) depends on the two dimensionless coefficients, (i.e., the discharge coefficient $C_{\mathrm{d}}$ and the wind coefficient $C_{\mathrm{w}}$ ). However, these coefficients are usually determined by in situ measurements and differ from greenhouse to greenhouse, and depend on the design configuration of the vents, greenhouse location, orientation and environmental conditions. Several values for $C_{\mathrm{w}}$ in the range between 0.006 and 0.28 and for $C_{\mathrm{d}}$ between 0.4 and 0.848 are reported in the literature [5-7]. Estimation of $\dot{m}_{\mathrm{a}}$ using Eq. (1) requires values of $C_{\mathrm{d}}$ and $C_{\mathrm{w}}$ to be determined carefully for the greenhouse under consideration because any inappropriate choice for the values of these coefficients results in a large error in the value of $\dot{m}_{\mathrm{a}}$.

(iii) Energy balance models: In such models, sensible heat balances are applied to the greenhouse air. In the 1980s, a simple design formula was suggested to estimate $\dot{m}_{\text {a }}$ based on the fundamental heat balance of the greenhouse [8]. Assuming the air is completely mixed, this formula is given by [8] as:

$$
\dot{m}_{\mathrm{a}}=\frac{S_{\mathrm{o}} \tau_{\mathrm{c}} A_{\mathrm{f}}-U A_{\mathrm{c}} \Delta T}{\Delta I}, \quad(\Delta I>0.0)
$$

This equation has been modified, based on the sensible heat balance of the greenhouse air, to be the ASAE standard design formula and reported in [9] in the form:

$$
\dot{m}_{\mathrm{a}}=\frac{(1-\delta) \tau_{\mathrm{c}} S_{\mathrm{o}} A_{\mathrm{f}}-U A_{\mathrm{c}} \Delta T}{C_{\mathrm{pa}} \Delta T}
$$


where $S_{\mathrm{o}}$ is the global solar radiation flux on a horizontal surface outside the greenhouse in $\mathrm{W} \mathrm{m}^{-2} ; \tau_{\mathrm{c}}$ is the average transmittance of the greenhouse cover to solar radiation; $A_{\mathrm{f}}$ and $A_{\mathrm{c}}$ is the surface area of the greenhouse floor and cover; $U$ is the overall heat loss coefficient of the cover in $\mathrm{W} \mathrm{m}^{-2} \mathrm{C}^{-1} ; \Delta I$ is the moist air specific enthalpy difference between inside and outside the greenhouse $\left(I_{\mathrm{i}}-I_{\mathrm{o}}\right)$ in $\mathrm{J} \mathrm{kg}^{-1}$ of dry air; $C_{\mathrm{pa}}$ is the specific heat of air at constant pressure and $\delta$ is an "evaporation coefficient", which estimates the fraction of total solar radiation load taken up by evaporation in the greenhouse. No details are given in the literature for the proper selection of $\delta$, and standard examples often use $\delta=0.5$ [9]. The term $(1-\delta) \tau_{\mathrm{c}}$ in Eq. (3) is also defined as the solar radiation heating factor $\eta$, (i.e. the fraction of $S_{\mathrm{o}}$ that was converted to sensible heat and used to warm up the greenhouse air). Several values of $\eta$ are reported in the range between 0.3 and $0.7[10,11]$. Determination of $\delta$ as well as $\eta$ value is quite difficult, especially if the greenhouse includes a crop canopy and associated with an evaporative cooling in summer. Limitations of using Eq. (2) as reported in [8] are: $S_{\mathrm{o}}>230 \mathrm{~W} \mathrm{~m}^{-2} ; \Delta I>8.368 \mathrm{~kJ} \mathrm{~kg}^{-1}$ and the time interval should be higher than $20 \mathrm{~min}$. In summer, values of $\Delta I$ and $\Delta T$ in Eq. (2) and Eq. (3) are always positive during the daytime, even though, these equations resulted in negative values of $\dot{m}_{\mathrm{a}}$ in the morning and afternoon (at low solar radiation levels).

In addition to Eq. (1) and Eq. (2), several previous studies estimated the natural ventilation rate of greenhouses by using energy balance methods. All of these studies assumed that solar radiation transmitted into the greenhouse was the only input energy and used an average value of the cover transmittance $\left(\tau_{c}\right)$. However, $\tau_{c}$ depends on the spatial location within the greenhouse and on the altitude of the greenhouse. The maximum longitudinal cross sectional variation of $\tau_{\mathrm{c}}$ over the floor surface in a venlotype N-S glasshouse ( $4 \mathrm{~mm}$ thick of cover) was measured by [12] at the location $52^{\circ}$ $20^{\prime} \mathrm{N}$ to be 0.4 . Maximum spatial variation of $\tau_{\mathrm{c}}$ was measured by [13] in a scale model of a glasshouse ( $4 \mathrm{~mm}$ thick of cover) at the location $37^{\circ} 58^{\prime} \mathrm{N}$ to be 0.8 . Accordingly, using an average value of $\tau_{c}$ will cause a large error in the estimation of the transmitted solar radiation into the greenhouse and in the estimation of $\dot{m}_{\mathrm{a}}$ as well. This error is expected to be high in small greenhouses because the cover to floor surface area ratio is usually high (e.g., 3 5), and unfortunately most of the ventilation studies using an energy balance method or any other method were based on small greenhouses (i.e. experimental greenhouses).

The objectives of this study were to: (i) develop a simplified energy balance model that can be used to estimate the natural ventilation of greenhouses precisely, and (ii) check the validity of the model by comparing its results with results of other theoretical models and with results of experimental measurements reported in the literature. In this model, uncertain parameters and assumptions those may cause errors, such as the thermal inertia of the greenhouse soil and using an average value of $\tau_{c}$ were excluded. Therefore, the energy balance was applied to a control volume for the greenhouse suggested to be between the outer surface of the cover and the floor surface. 


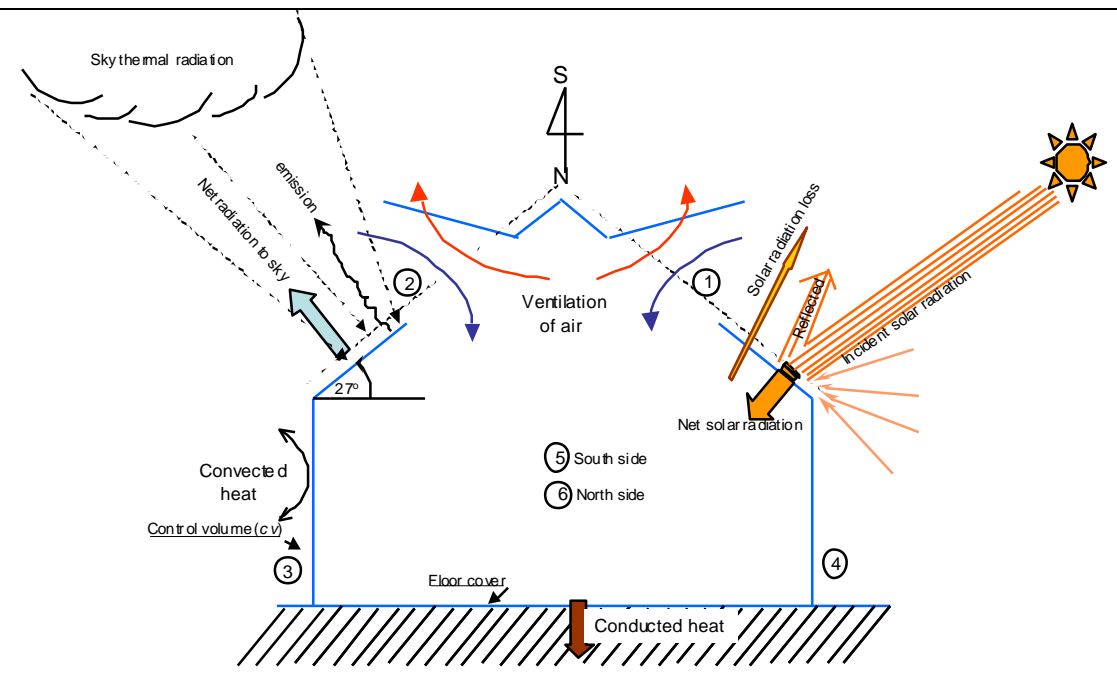

Fig. 1 Schematic diagram of the greenhouse and its control volume $(c v)$, and the different modes of energy exchange.

\section{THE MODEL DESCRIPTION}

The greenhouse used in this study (Fig. 1) is a single-span; its frame was constructed from aluminum bars and covered with a glass sheet, $4 \mathrm{~mm}$ thick. The greenhouse was considered as a thermodynamic system, enclosed by a control volume $(c v)$. The different modes of energy crossing the boundary of the system (i.e. the $c v$ ) are illustrated in Fig. 1. During the daytime, the cover surfaces (i.e. surface 1 to surface 6) were found to have almost the same temperature because the cover absorptance is not strongly affected by either the incident angle of solar radiation or the surface orientation [14]. Therefore, measuring $T_{\mathrm{c}}$ of one or two surfaces is sufficient to represent the temperature of the whole cover surfaces. Energy balance was applied to the $c v$ under the un-steady state condition assuming: (i) The moist air inside and outside the greenhouse is well mixed and characterized by average dry and wet bulb temperatures $\left(T_{\mathrm{di}}, T_{\mathrm{wi}}, T_{\mathrm{do}}, T_{\mathrm{wo}}\right)$ and average thermo-physical properties. (ii) The cover and floor are gray surfaces in terms of long wave radiation and characterized by an equivalent temperatures $\left(T_{\mathrm{c}}\right.$ and $T_{\mathrm{f}}$ ). (iii) The cover is opaque to incident thermal radiation and reflects the thermal radiation diffusively and the floor surface reflects solar and thermal radiation diffusively. (iv) Parameters in the upcoming analysis are time dependent. To simplify the expressions, the functional relationship of time $t$ is omitted from all the symbols hereafter. Energy terms are crossing the $c v$ of the system (Fig. 1), in and out, are: sensible and latent heat associated with the ventilation process $\left(I_{\mathrm{o}} \dot{m}_{\mathrm{a}}\right.$ and $\left.I_{\mathrm{i}} \dot{m}_{\mathrm{a}}\right)$; solar radiation $\left(S_{\mathrm{n}}\right)$; convection exchange between the outer surface of the cover and the outside ambient air $\left(Q_{\mathrm{c}-\mathrm{o}}\right)$; thermal radiation exchange between the outer surface of cover and sky $\left(R_{\mathrm{n}}\right)$; and the conducted heat into the greenhouse soil $\left(q_{\mathrm{o}}\right)$. Determinations of these terms are as follows: 


\subsection{Solar Radiation}

The different surfaces of the greenhouse cover were designated with the numbers 1 to 6 (Fig. 1), and all the surfaces were supposed to be facing outward. The slope and azimuth angles of these surfaces $\left(\beta^{o}, \gamma_{s}^{o}\right)$ are determined. The total solar irradiance received by a tilted surface $j, S_{\mathrm{t}, j}(j=1,2, . .6)$ is given by [15] as:

$S_{\mathrm{t}, j}=\left(S_{\mathrm{b}, \mathrm{t}}+S_{\mathrm{d}, \mathrm{t}}+S_{\mathrm{gr}, \mathrm{t}}\right)_{j}$

where $S_{\mathrm{b}, \mathrm{t}}$ is the beam irradiance; $S_{\mathrm{d}, \mathrm{t}}$ is the sky diffuse irradiance and $S_{\mathrm{gr}, \mathrm{t}}$ is the global irradiance which is received by the tilted surface $j$ from that reflected from the ground outside the greenhouse. Assuming the sky diffuse irradiance is anisotropic, Eq. (4) can be rewritten in the form [15]

$S_{\mathrm{t}, j}=S_{\mathrm{o}}\left\{\begin{array}{l}\left.\left(1-f_{\mathrm{d}}\right) r_{\mathrm{b}}+f_{\mathrm{d}} \cos ^{2}\left(\frac{\beta}{2}\right)\left(1+F \sin ^{3}\left(\frac{\beta}{2}\right)\right)\left(1+F \cos ^{2} \theta \sin ^{3} \theta_{\mathrm{z}}\right)\right\}_{\mathrm{gr}} \sin ^{2}\left(\frac{\beta}{2}\right)\end{array}\right\}_{j}$

with $F=1-\left(f_{\mathrm{d}}\right)^{2}$ and

$$
\begin{aligned}
r_{\mathrm{b}} & =\frac{\cos \theta}{\cos \theta_{\mathrm{z}}}, & & \text { if } 0^{\circ} \leq \theta<90^{\circ} \\
& =0 \quad & & \text { if } \theta \geq 90^{\circ}
\end{aligned}
$$

where $r_{\mathrm{b}}$ is the ratio of beam irradiance received by a tilted surface $j$ to that received by a horizontal surface; $f_{\mathrm{d}}$ is the ratio of diffuse to global solar radiation. Variation of $f_{\mathrm{d}}$ with time of sunny days in the Tokyo area $\left(139.46^{\circ} \mathrm{E}\right.$, longitude and $35.41^{\circ} \mathrm{N}$, latitude), Japan are reported in [16] and value of $f_{\mathrm{d}}$ was taken to be 0.15 on average; $\theta$ and $\theta_{\mathrm{z}}$ are the incident and azimuth angles of the solar beam on the surface $j$; $S_{\mathrm{o}}$ is the outside global solar radiation received by a horizontal surface; and $\rho_{\mathrm{gr}}$ is the reflectance of the ground to beam solar radiation and was taken to be 0.2 with no snow on the vegetated ground [15]. Values of $\theta$ and $\theta_{z}$ can be estimated at any time of the day using the well known relations reported in [15]. The net solar energy entering the $c v$ at the outside of the cover surfaces (Fig. 1) as a function of time, or $\theta$ as well, can be estimated as:

$S_{\mathrm{n}}=\sum_{j=1}^{6} A_{j} S_{\mathrm{t}, j}\left(1-\bar{\rho}_{\mathrm{c}, j}-\xi_{j}\right)$

where $\bar{\rho}_{\mathrm{c}, j}$ is the net reflectance at the outside surface of the cover surface $j$ in relation to the global solar radiation and $A_{j}$ is the area of the surface $j$. The transmitted solar radiation from each surface $j$ is assumed to be suffering multiple diffusive reflections between the cover and floor surfaces; a fraction of which is transmitted back to the outside $\left(\xi_{j}\right)$. The diffuse solar radiation inside and outside the greenhouse was treated as direct beam incident on the inner surface of the cover at an incidence angle $\theta$ of $60^{\circ}$ 
[15]. For each surface $j$ of a greenhouse without crop canopy, the value of $\xi_{j}$ can be estimated as:

$$
\xi_{j}=\left(\frac{\bar{\tau}_{\mathrm{c}, j} \tau_{\mathrm{c}, j} \rho_{\mathrm{f}} F_{j-\mathrm{f}} F_{\mathrm{f}-j}}{1-\rho_{\mathrm{f}} \rho_{\mathrm{c}, j} F_{j-\mathrm{f}} F_{\mathrm{f}-j}}\right)
$$

where $\tau_{\mathrm{c}, j}$ and $\iota_{\mathrm{c}, j}$ are the net transmittance and reflectance of the cover surface $j$ to direct solar radiation estimated at $\theta$ of $60^{\circ} ; F_{\mathrm{f}-j}$ and $F_{j-\mathrm{f}}$ are the view factors between the floor and the surface $j$ and between the surface $j$ and the floor, respectively and $\bar{\tau}_{\mathrm{c}, j}$ is the net transmittance of the cover surface $j$ in relation to the global solar radiation. The fraction of solar radiation that is transmitted backward to outside the greenhouse from the cover surfaces was estimated to be in the range from 0.05 to 0.07 [17]. Therefore, values of $F_{\mathrm{f}-\mathrm{j}}$ and $F_{j-\mathrm{f}}$ can be assumed to equal one without jeopardizing the accuracy of solution. The floor reflectance to the global solar radiation $\rho_{\mathrm{f}}$ was taken to be 0.2 [18]. Values of $\bar{\rho}_{\mathrm{c}, j}$ and $\bar{\tau}_{\mathrm{c}, j}$ can be estimated from [16] as:

$$
\bar{\rho}_{\mathrm{c}, j}=f_{\mathrm{d}} \rho_{\mathrm{c}, j}+\left(1-f_{\mathrm{d}}\right) \rho_{\mathrm{c}, j} \quad \text { and } \quad \bar{\tau}_{\mathrm{c}, j}=f_{\mathrm{d}} \tau_{\mathrm{c}, j}+\left(1-f_{\mathrm{d}}\right) \tau_{\mathrm{c}, j}
$$

In Eq. (9), $\tau_{\mathrm{c}, j}$ and $\rho_{\mathrm{c}, j}$ are the net directional tansmittance and reflectance of the cover surface $j$ in relation to the direct solar radiation, respectively. The radiative properties of the glass cover (values of $\tau_{\mathrm{c}, j}$ and $\rho_{\mathrm{c}, j}$ ) at a specified incidence angle $\theta$ are given, respectively by [16]:

$$
\begin{aligned}
\tau_{\mathrm{c}, j} & =\frac{\hat{\tau}(1-\hat{\rho})^{2}}{1-(\hat{\tau} \hat{\rho})^{2}} \\
\rho_{\mathrm{c}, j} & =\hat{\rho}\left(1+\hat{\tau} \tau_{\mathrm{c}, j}\right)
\end{aligned}
$$

In Eqs. (10) and (11), the directional transmittance due to absorption $(\hat{\tau})$ and the interface reflectance $(\hat{\rho})$ of a cover sheet having a thickness $d$ and an absorption coefficient $\kappa$ are given by:

$$
\hat{\tau}=\mathrm{e}^{-\left(\kappa d / \cos \theta_{r}\right)} \quad \text { and } \quad \hat{\rho}=\frac{1}{2}\left\{\frac{\sin ^{2}\left(\theta_{\mathrm{r}}-\theta\right)}{\sin ^{2}\left(\theta_{\mathrm{r}}+\theta\right)}+\frac{\tan ^{2}\left(\theta_{\mathrm{r}}-\theta\right)}{\tan ^{2}\left(\theta_{\mathrm{r}}+\theta\right)}\right\}
$$

The angle of refraction $\left(\theta_{\mathrm{r}}\right)$ of a solar beam passing through the cover sheet related to the refractive index $(n)$ of the cover material is defined by:

$\theta_{\mathrm{r}}=\sin ^{-1}(\sin \theta / n)$

Values of $n$ and $\kappa$ were taken to be 1.526 and $0.3 \mathrm{~cm}^{-1}$, respectively [15] 


\subsection{Thermal Radiation Exchange}

For single-span greenhouses (e. g. Fig. 1) the view factor between the outer surface of the cover and the sky dome is assumed to be equal to one. The net thermal radiation exchange between the outer surface of the cover having an emittance $\varepsilon_{\mathrm{c}}$ and an average temperature $T_{\mathrm{c}}$ and the assumed black sky dome at an equivalent temperature $T_{\text {sky }}$ is given by [15] as:

$R_{\mathrm{n}}=\varepsilon_{\mathrm{c}} A_{\mathrm{c}} \sigma\left(T_{\mathrm{c}}^{4}-T_{\mathrm{sky}}^{4}\right)$

with $T_{s k y}$ is in Kelvin and is given by [19] as:

$\left.T_{\text {sky }}=0.0559 T_{\text {do }}\right)^{1.5}$

where $T_{\mathrm{do}}$ is the outside dry bulb temperature in Kelvin.

\subsection{Convection Exchange}

The convective heat exchange between the outer surfaces of the cover and the outside ambient air $Q_{\text {c-o }}$ can be estimated using Newton's law of cooling with a convective heat transfer coefficient $h_{\mathrm{c}-\mathrm{o}}$ reported in [19] for the forced convection condition over buildings as:

$$
Q_{\mathrm{c}-\mathrm{o}}=A_{\mathrm{c}} h_{\mathrm{c}-\mathrm{o}}\left(T_{\mathrm{c}}-T_{\mathrm{do}}\right), \quad h_{\mathrm{c}-\mathrm{o}}=\max \left(5, \frac{8.6 V^{0.6}}{L_{\mathrm{c}}^{0.4}}\right), \quad L_{\mathrm{c}}=\sqrt[3]{V_{\mathrm{g}}}
$$

where $V$ is the wind speed outside the greenhouse and $V_{\mathrm{g}}$ is the greenhouse volume.

\subsection{Conduction Exchange}

The nature of heat conduction in the greenhouse soil is quite complex, it depends on the soil composition, the soil thermo-physical properties and the soil water contents. For simplicity, the floor soil was assumed to behave as a homogeneous layer having a thickness $z$, an equivalent thermal conductivity $k_{\mathrm{f}}$, an upper surface temperature $T_{\mathrm{f}}$ and a lower constant subsoil temperature $T_{\infty}$ (i.e. unaffected by the daily variation of $T_{\mathrm{f}}$ ). The heat flux $q_{\mathrm{o}}$ crossing the $c v$ downward and conducted into the floor soil, assuming quasi-steady state conditions at small time intervals $(d t=5 \mathrm{~s})$, can be approximated as [17]:

$q_{\mathrm{o}} \cong \frac{k_{\mathrm{f}} A_{\mathrm{f}}\left(T_{\mathrm{f}}-T_{\infty}\right)}{z}$

where $A_{\mathrm{f}}$ is the floor surface area. Values of $k_{\mathrm{f}}, z$ and $T_{\infty}$ were taken to be $2.0 \mathrm{~W} \mathrm{~m}^{-1} \mathrm{C}^{-1}$, $0.5 \mathrm{~m}$, and $20 \mathrm{C}$, respectively [18].

\subsection{Energy Balance}

Energy balance was applied to the $c v$ of the greenhouse (Fig. 1) under the un-steady state condition according to the following equation:

$$
\left(S_{\mathrm{n}}+\dot{m}_{\mathrm{a}} I_{\mathrm{o}}\right)-\left(R_{\mathrm{n}}+Q_{\mathrm{c}-\mathrm{o}}+q_{\mathrm{o}}+\dot{m}_{\mathrm{a}} I_{\mathrm{i}}\right)=\left(m C_{\mathrm{p}} \frac{d T}{d t}\right)_{c v}
$$

The energy terms on the left hand side of Eq. (18) are as follows: $S_{\mathrm{n}}$ can be estimated from Eq. (7) by measuring $S_{\mathrm{o}}$ on a horizontal plane outside the greenhouse; $R_{\mathrm{n}}$ and $Q_{\text {c-o }}$ 
can be estimated from Eq. (13) and Eq. (15), respectively, by measuring $T_{\mathrm{c}}$ and $T_{\mathrm{do}} ; q_{\mathrm{o}}$ can be estimated from Eq. (17) by measuring $T_{\mathrm{f}}$; and the specific enthalpy of the moist air, in $\mathrm{kJ} \mathrm{kg}^{-1}$, inside and outside the greenhouse $\left(I_{\mathrm{i}}\right.$ and $\left.I_{\mathrm{o}}\right)$ can be approximated as a function of the dry bulb temperature and absolute humidity $\omega$ from [17] as:

$$
I=(1.007 T-0.026)+\omega(2501+1.84 T), \quad T \text { in }{ }^{\circ} \mathrm{C}
$$

The right hand side of Eq. (18) is the rate of stored energy of the masses enclosed in the $c v$, in which the mass $m$, the specific heat $C_{\mathrm{p}}$ and the change of temperature history (i.e. $d T / d t$ ) were counted for the glass cover, the aluminum frame, (assuming its temperature is the same as $T_{\mathrm{c}}$ ), and the greenhouse air. The unknown in Eq. (18) is the ventilation rate of air $\left(\dot{m}_{\mathrm{a}}\right)$, which can be determined by solving this equation at each time interval. Once the value of $\dot{m}_{\mathrm{a}}$ is determined, the number of greenhouse air changes per hour $\left(N_{\mathrm{a}}\right)$ can be determined as:

$$
N_{\mathrm{a}}=\dot{m}_{\mathrm{a}} \times 3600 /\left(V_{\mathrm{g}} \rho_{\mathrm{a}}\right)
$$

where $\rho_{\mathrm{a}}$ is the density of moist air in the greenhouse.

\section{EXPERIMENTAL MEASUREMENTS}

An experiment to measure the required environmental parameters to be used in solving Eq. (17) was conducted in a $26 \mathrm{~m}^{2}$ glass-covered greenhouse without crop canopy (Fig. 1). The greenhouse was oriented in a N-S direction on the Matsudo campus, Chiba University (Tokyo area, Japan, $139.46^{\circ} \mathrm{E}$, longitude and $35.41^{\circ} \mathrm{N}$, latitude). The greenhouse was naturally ventilated using two roof openings $(0.6 \mathrm{~m} \times 5$ $\mathrm{m}$ ), which were automatically opened for $T_{\mathrm{di}} \geq 28{ }^{\circ} \mathrm{C}$. The floor soil was covered with a black PVC plastic sheet to prevent the evaporation from the soil into the greenhouse air. The measurements were carried out on four sunny days (Sept. 29 to Oct 2, 2005) from 5:00 to 17:00. Measured parameters were: (i) the dry and wet bulb temperatures inside and outside the greenhouse $\left(T_{\mathrm{di}}, T_{\mathrm{wi}}\right.$, and $\left.T_{\mathrm{do}}, T_{\mathrm{wo}}\right)$ using aspirated psychrometers, (ii) the outside wind speed ( $V$ ) using PGWS-100 wind sonic anemometer (accuracy of $\pm 2 \% / 12 \mathrm{~m} \mathrm{~s}^{-1}$, Gill England) measured at $4 \mathrm{~m}$ above the ground level outside the greenhouse, (iii) the downward solar radiation flux outside and inside the greenhouse $\left(S_{\mathrm{o}}\right.$ and $\left.S_{\mathrm{i}}\right)$ using an MS-100 solarmeters (accuracy of $\pm 5 \%$, EKO-Instruments Trading Co. Ltd., Japan), (iv) the cover surface temperature $\left(T_{\mathrm{c}}\right)$ using two thermocouple junctions (copper constantan type-T) of $0.3 \mathrm{~mm}$ in diameter were smoothly attached to the outside of the cover surfaces 1 and 5 and the average value of $T_{\mathrm{c}}$ was obtained and (v) the floor surface temperature $\left(T_{\mathrm{f}}\right)$ using four thermocouple junctions $(0.3 \mathrm{~mm}$ in diameter) smoothly attached to the floor surface at different locations. To avoid the shading effect of the aluminum frame on the floor junctions, the highest value of $T_{\mathrm{f}}$ was considered. The measuring technique for $T_{\mathrm{c}}$ and $T_{\mathrm{f}}$ was reported in [14], in which, the thermocouple junctions on the cover and floor surfaces were kept exposed to radiation and all were calibrated before use. The effect of radiation on these junctions was excluded by using a correction factor; however, the effect of the air current $\left(V<5 \mathrm{~m} \mathrm{~s}^{-1}\right)$ on the junction measurements can be neglected [14]. The 
correction factor gives the temperature difference, in ${ }^{\circ} \mathrm{C}$ that should be subtracted from the measured values of $T_{\mathrm{c}}$ and $T_{\mathrm{f}}$ and is given by [14] as:

$\Delta T=-0.22+5.11\left(1.0-e^{-0.0024 S}\right), \quad r^{2}=0.94$

where $S$ is the incident solar radiation flux on a horizontal plane at the junction level. The parameters were measured at 5-s intervals and recorded in a data logger (CR23X Micrologger, Campbell Scientific, Inc.). The average value of the cover transmittance $\left(\tau_{c}\right)$ was estimated to be 0.7 during the period of the experiment.

\section{RESULTS AND DISCUSSION}

\subsection{The Greenhouse Environment}

The average values of the parameters required for solving Eq. (18) for every $30 \mathrm{~min}$ are illustrated in Fig. 2 and Fig. 3. Figure 2 shows the time courses of $T_{\mathrm{di}}, T_{\mathrm{do}}, T_{\mathrm{c}}$ and $T_{\mathrm{f}}$. Values of $T_{\mathrm{f}}$ are the highest because the greenhouse was without crop canopy under a sunny weather. Values of $T_{\mathrm{c}}$ are relatively lower than $T_{\mathrm{di}}$ because the measurements were carried out in a mild season. However, in hot summer seasons, $T_{\mathrm{c}}$ is always higher than $T_{\mathrm{di}}$ due to the solar radiation absorbed by the cover material. In Fig. 3, the solar radiation flux outside the greenhouse $\left(S_{\mathrm{o}}\right)$ and inside and outside relative humidity $\left(R H_{\mathrm{i}}\right.$ and $\left.R H_{\mathrm{o}}\right)$ are illustrated. Values of $R H_{\mathrm{i}}$ and $R H_{\mathrm{o}}$ were estimated from the measured values of $T_{\mathrm{di}}, T_{\mathrm{wi}}, T_{\mathrm{do}}$ and $T_{\mathrm{wo}}$ and using the well known psychrometric relations. Figure 3 shows high $R H_{\mathrm{i}}$ in the morning and afternoon when the vents were closed and the $T_{\mathrm{di}}$ was low.

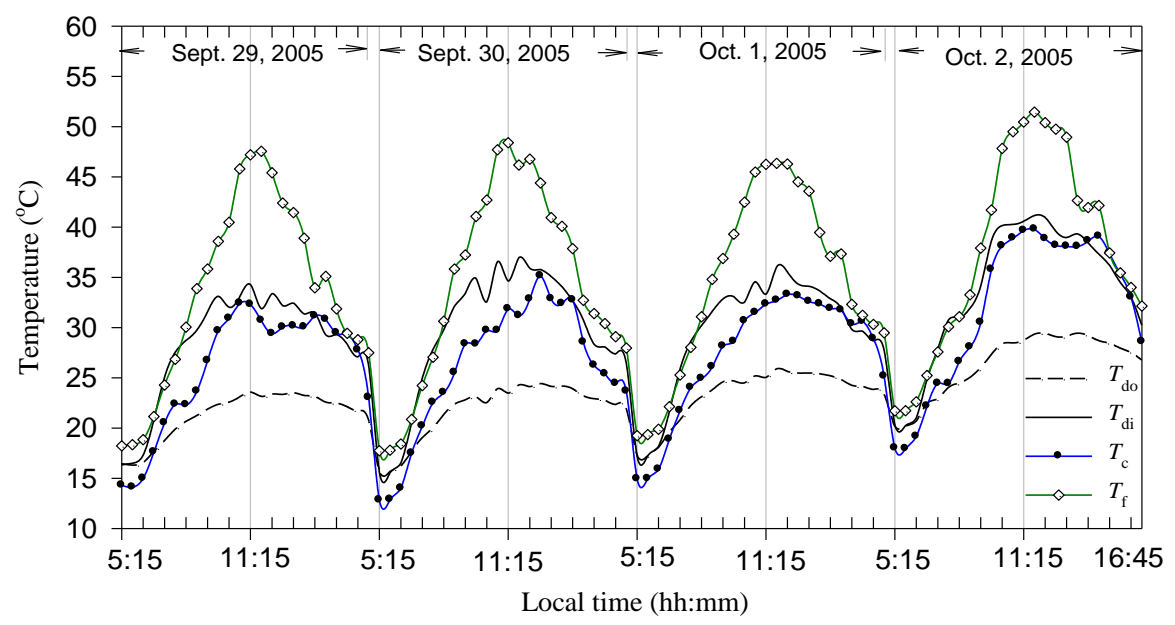

Fig. 2 Time courses of the measured values of the dry bulb temperatures outside and inside the greenhouse $\left(T_{\mathrm{do}}, T_{\mathrm{di}}\right)$, the cover surface temperature $\left(T_{\mathrm{c}}\right)$ and the floor surface temperature $\left(T_{\mathrm{f}}\right)$. 


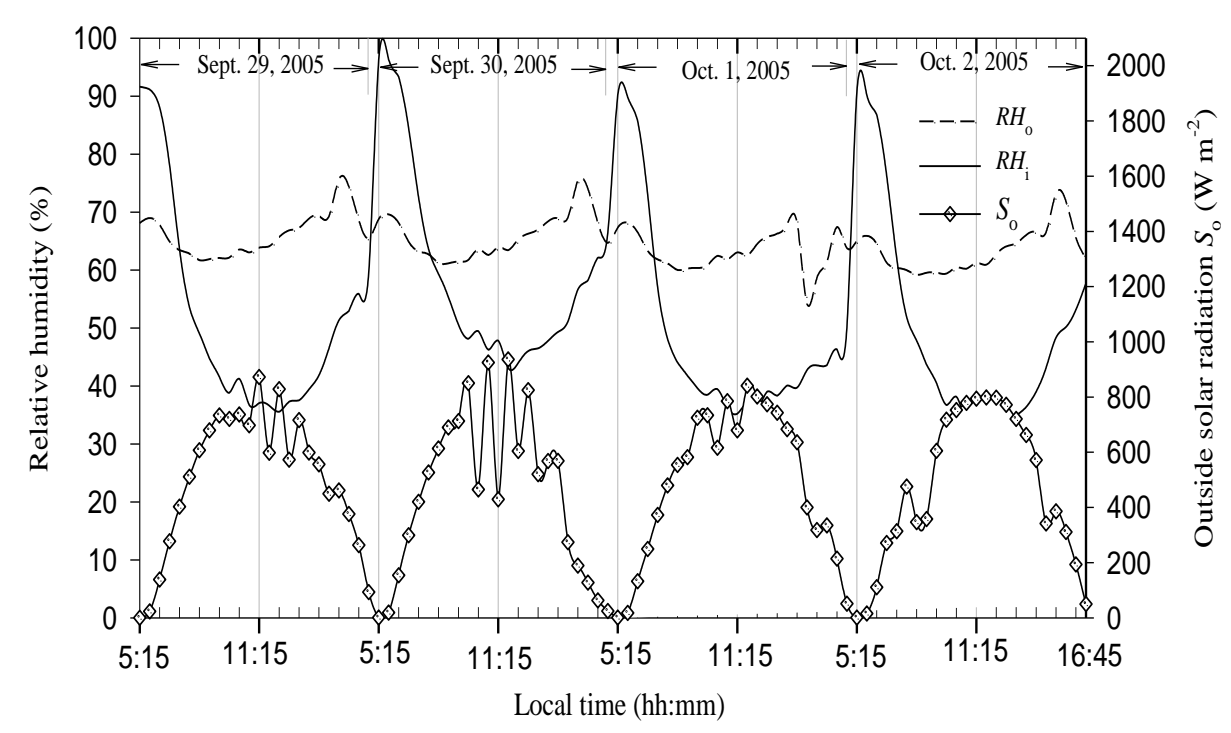

Fig. 3 Time courses of the solar radiation flux measured outside the greenhouse $\left(S_{0}\right)$ and the relative humidity estimated inside and outside the greenhouse $\left(R H_{\mathrm{i}}, R H_{\mathrm{o}}\right)$.

\subsection{Energy Exchange with the $C V$ of the Greenhouse}

The rates of energy gained and lost by the greenhouse system (i.e. input and output energy crossing the $c v$ in Fig. 1) are illustrated in Fig. 4 and Fig. 5, respectively. Figure 4 illustrates the time courses of the net input solar energy to the greenhouse $c v$ estimated using two methods: (i) The present model, i.e., the net solar radiation flux crossing the $c v\left(S_{\mathrm{n}}\right)$ estimated using Eq. (7) per unit area of floor, and (ii) using the measured average values of $\tau_{\mathrm{c}}$, i.e., $S_{\mathrm{i}}\left(S_{\mathrm{i}}=0.7 \times S_{\mathrm{o}}\right)$. If the absorbed portion by the glass cover (assuming $\alpha_{\mathrm{c}}=0.15$ for $4 \mathrm{~mm}$ thick glass sheet) was subtracted from $S_{\mathrm{n}}$, one can recognize the difference between the transmitted solar radiation in each case. Accordingly, assuming an average value for $\tau_{\mathrm{c}}$ would result in a large error in the estimation of the transmitted solar radiation as well as the energy balance of the greenhouses. In the present model, use of $\tau_{\mathrm{c}}$ was avoided by treating the solar radiation at the outside of the cover surfaces. However, the directional transmittance of each cover surface $\left(\tau_{\mathrm{c}, \mathrm{j}}\right)$ was considered only to estimate the fraction of solar radiation losses from each surface to outside the greenhouse, $\xi_{\mathrm{j}}$. 


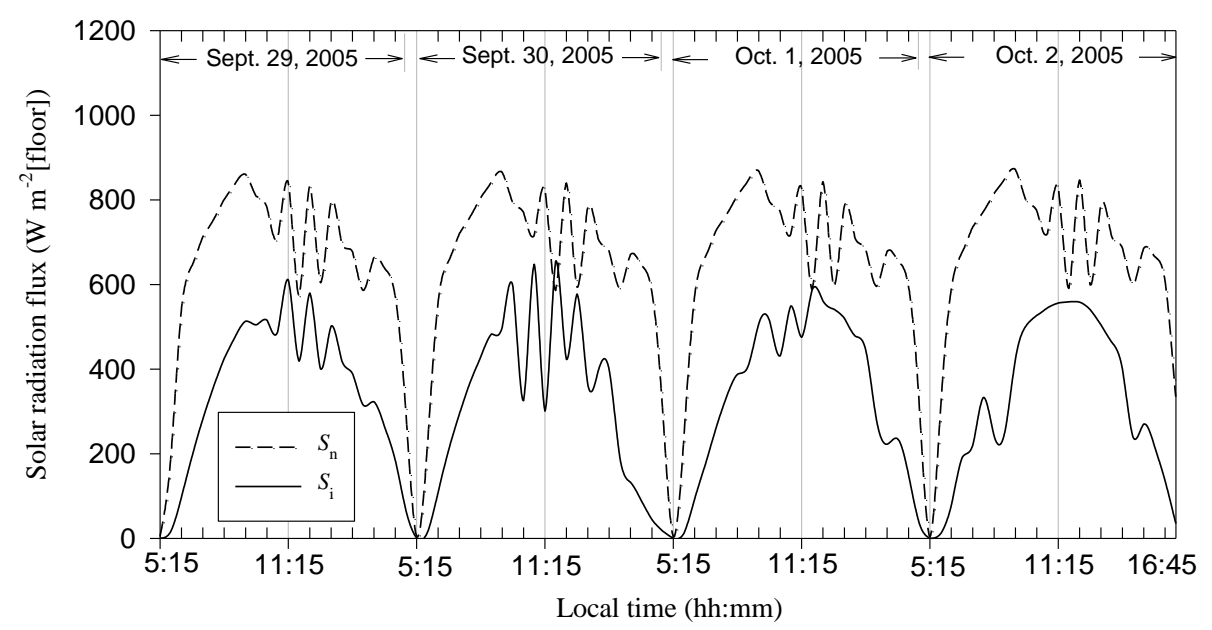

Fig. 4 Time courses of the net solar radiation flux estimated by using the present model $\left(S_{\mathrm{n}}\right)$, and the transmitted solar radiation flux into the greenhouse $\left(S_{\mathrm{i}}\right)$, estimated by using an average value of $\tau_{c}$.

Figure 5 shows the time courses of the energies are crossing the $c v$. These energies are: heat conduction to or from the soil, $\left(q_{0}\right)$ per unit area of floor; heat convection at the outer surface of the cover, $\left(Q_{\mathrm{c-o}}\right)$ per unit area of cover; and the net thermal radiation exchange between the outer surface of the cover and the sky, $\left(R_{\mathrm{n}}\right)$ per unit area of cover. In the early morning both the conductive and the convective heat $\left(q_{\mathrm{o}}\right.$ and $\left.Q_{c-0}\right)$ are input to the $c v$. Because, at that time the soil releases heat into the greenhouse air and the cover temperature $T_{\mathrm{c}}$ is lower than $T_{\mathrm{do}}$. However, under daytime conditions, the greenhouse cover always loses thermal radiation to the cold sky dome.

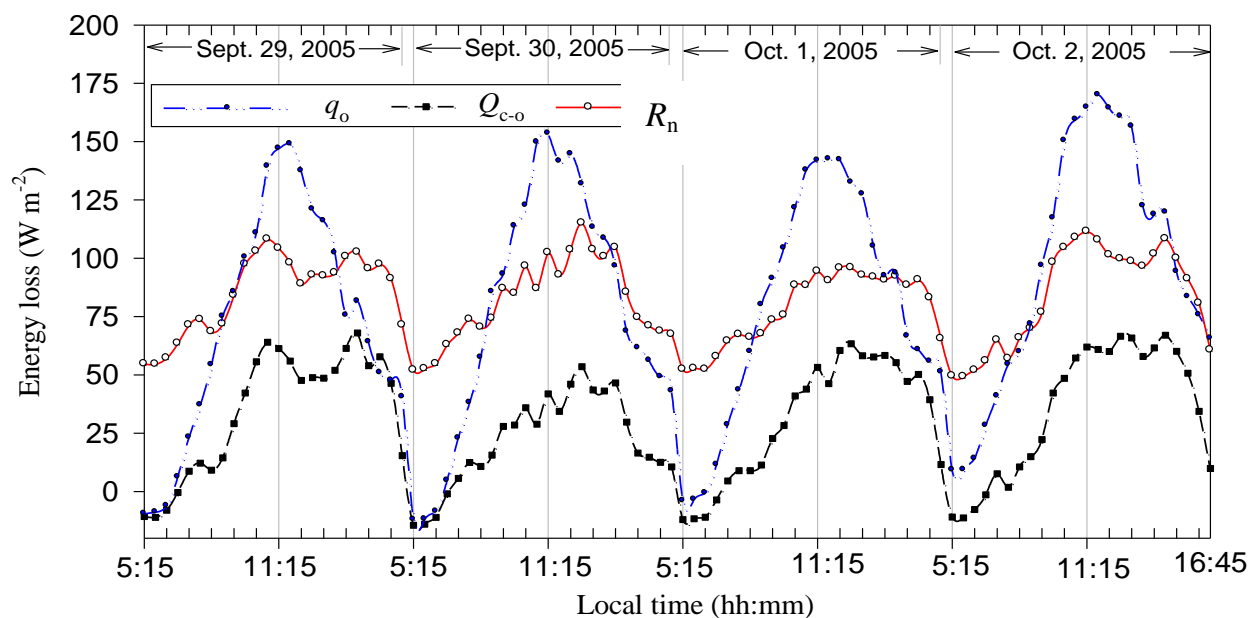

Fig. 5 Time courses of energies crossing the $c v$ those are: soil conduction $\left(q_{\mathrm{o}}\right)$, convection at the outer surface of the cover $\left(Q_{\mathrm{c}-\mathrm{o}}\right)$ and the net thermal radiation exchanges between the outer surface of the cover and sky $\left(R_{\mathrm{n}}\right)$. 


\subsection{Estimating the Ventilation Rate}

Previous studies had concluded that for wind speeds $(V)$ greater than $2 \mathrm{~m} \mathrm{~s}^{-1}$, the natural ventilation is mainly driven by the wind effect, and the buoyancy effect can be neglected. The effects of wind speed and the design configuration of vents opening on the natural ventilation have been examined by many studies. However, at low wind speeds such as in the present study ( $V$ was from $0 \mathrm{~m} \mathrm{~s}^{-1}$ to $2.5 \mathrm{~m} \mathrm{~s}^{-1}$ ), the daily behaviors of the natural ventilation as affected by the environment inside and outside the greenhouses received little attention in the previous studies. At low wind speeds, natural ventilation is driven by the combined wind and buoyancy effects and the one estimated based on the greenhouse thermal balance (as in the present study) strongly affected by the enthalpy difference $\Delta I$ between inside and outside the greenhouse. The enthalpy difference $\Delta I$ depends on the combined $\Delta T$ and the absolute humidity difference. Figure 6(a) illustrates the time courses of the ventilation rate $\left(\dot{m}_{\mathrm{a}}\right)$ and $\Delta I$ during the period of measurements when the ventilators are open. Figure 6(a) shows that the variations of $\dot{m}_{\mathrm{a}}$ are inversely related to the variations of $\Delta I$ (see Eq. 2) when the wind speed is low. Among the days of measurements, the value of $\dot{m}_{\mathrm{a}}$ was in the range between $0.12 \mathrm{~kg} \mathrm{~s}^{-1}$ and $2.25 \mathrm{~kg} \mathrm{~s}^{-1}$. The high values of $\Delta I$ on Sept. 30 are mainly due to the high relative humidity of the greenhouse air on that day (Fig. 3). The number of greenhouse air changes per hour $\left(N_{\mathrm{a}}\right)$ is sometimes used, as a general unit, to express the ventilation rate. In Fig. 6(b), the time course of the value of $N_{\mathrm{a}}$ corresponding to the value of $\dot{m}_{\mathrm{a}}$ is illustrated. The value of $N_{\mathrm{a}}$ was in the range between $5 \mathrm{~h}^{-1}$ and $58 \mathrm{~h}^{-1}$. These values are in the same order of magnitude of the values reported in [20], which were in the range between $20 \mathrm{~h}^{-1}$ and $60 \mathrm{~h}^{-1}$, for a single-span greenhouse with roof and side wall ventilators and $V$ was less than $4 \mathrm{~m} \mathrm{~s}^{-1}$.

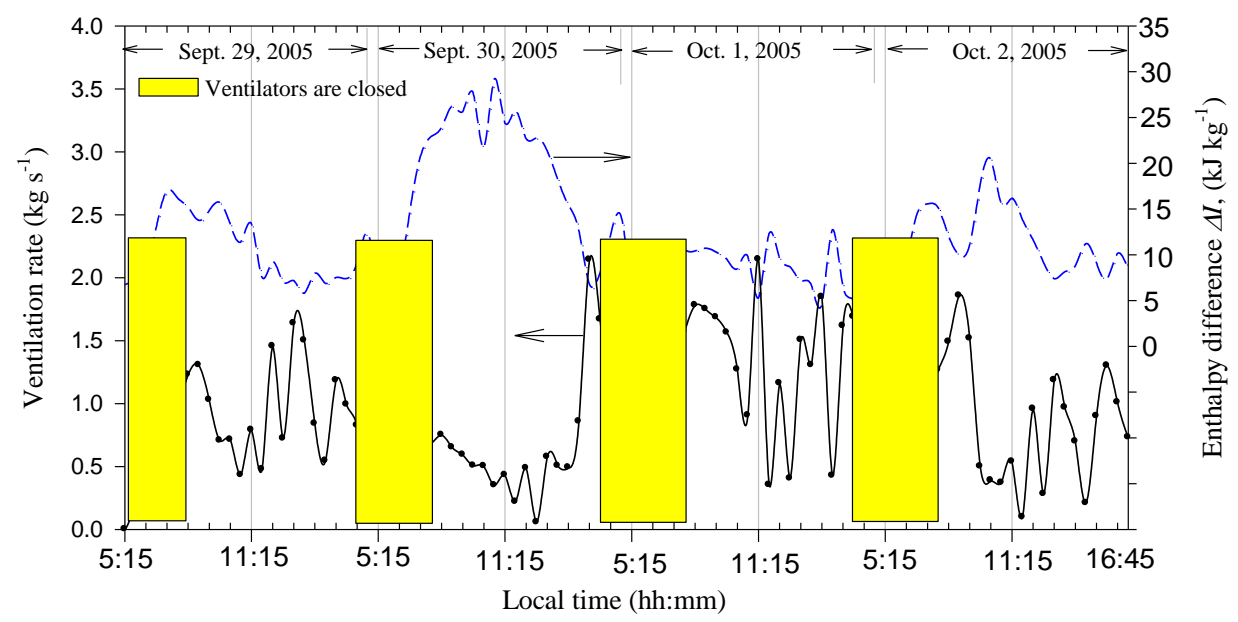

(a) 


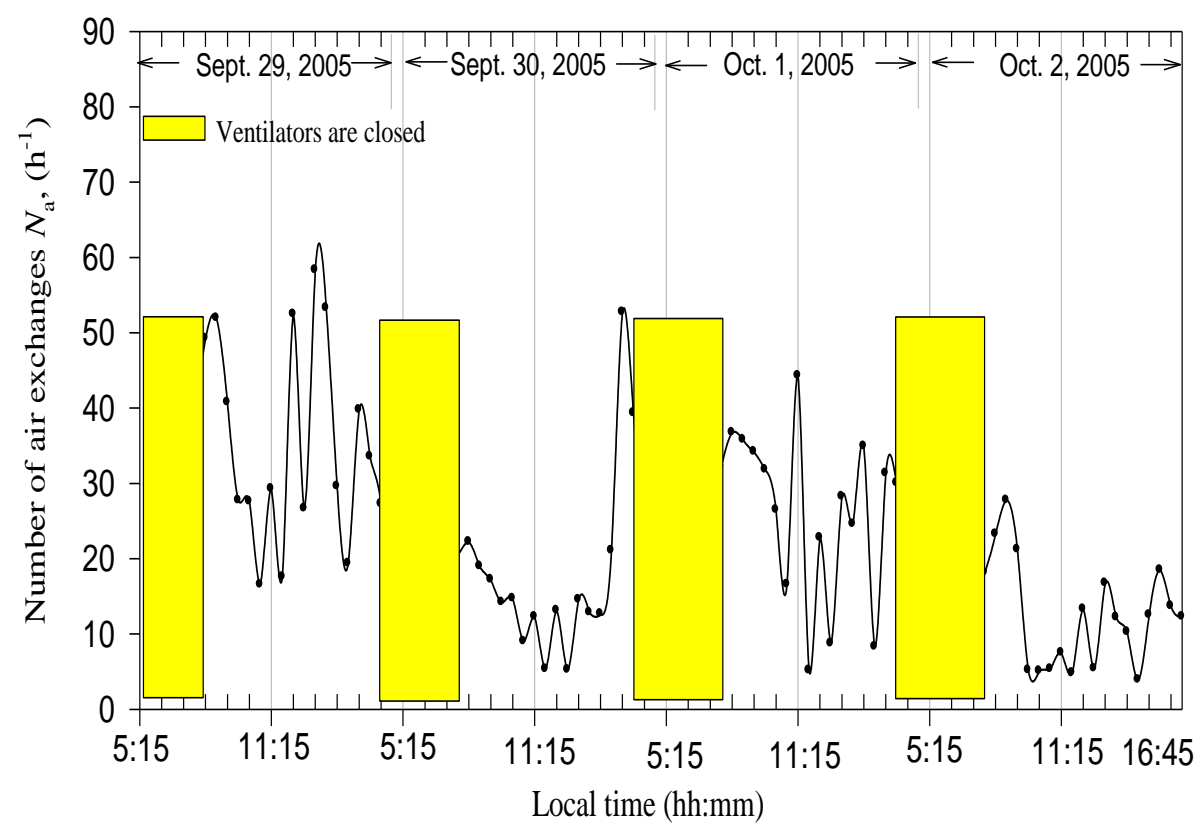

(b)

Fig. 6 Time courses of: (a) the natural ventilation rate $\left(\dot{m}_{\mathrm{a}}\right)$ and the enthalpy difference of air between inside and outside the greenhouse $(\Delta I)$, and (b) the number of the greenhouse air exchanges $\left(N_{\mathrm{a}}\right)$ per hour.

\subsection{The Present Model and Other Models}

During the periods when the ventilators are opened, the values of $\dot{m}_{\mathrm{a}}$ estimated using the present model were compared with those estimated using Eq. (2) (i.e. the fundamental heat balance), and Eq. (1) (i.e. air dynamic model). The results are illustrated in Fig. 7(a)-(d) for the four days, respectively. Two extreme values for $C_{\mathrm{w}}$ (i.e. 0.006 and 0.28 ) were considered to be used in Eq. (1) and the value of $C_{\mathrm{d}}$ was estimated according to [5] as a function of the vent opening angle $\phi\left(C_{\mathrm{d}}=\right.$ $0.64+0.001 \phi)$ and was kept constant. Three conclusions can be drawn from the data shown in Fig. 7(a)-(d): 


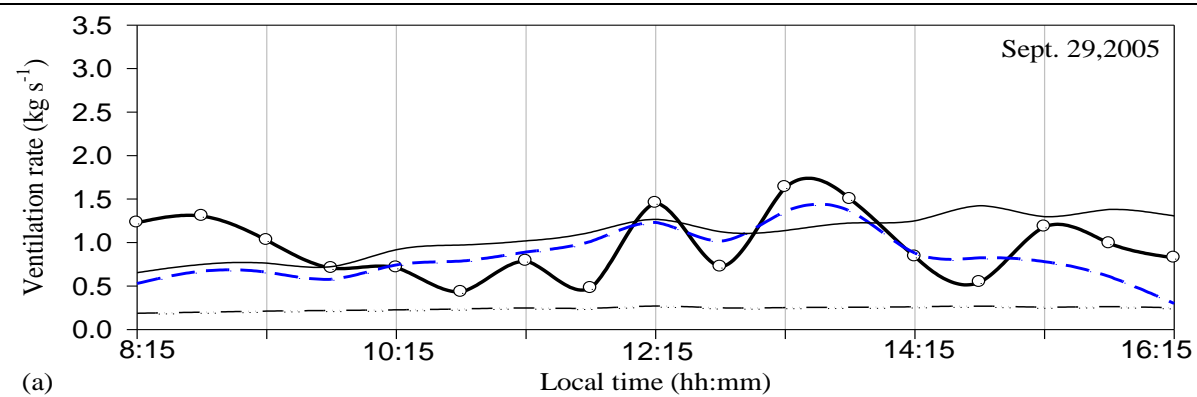

(a)

Local time (hh:mm)
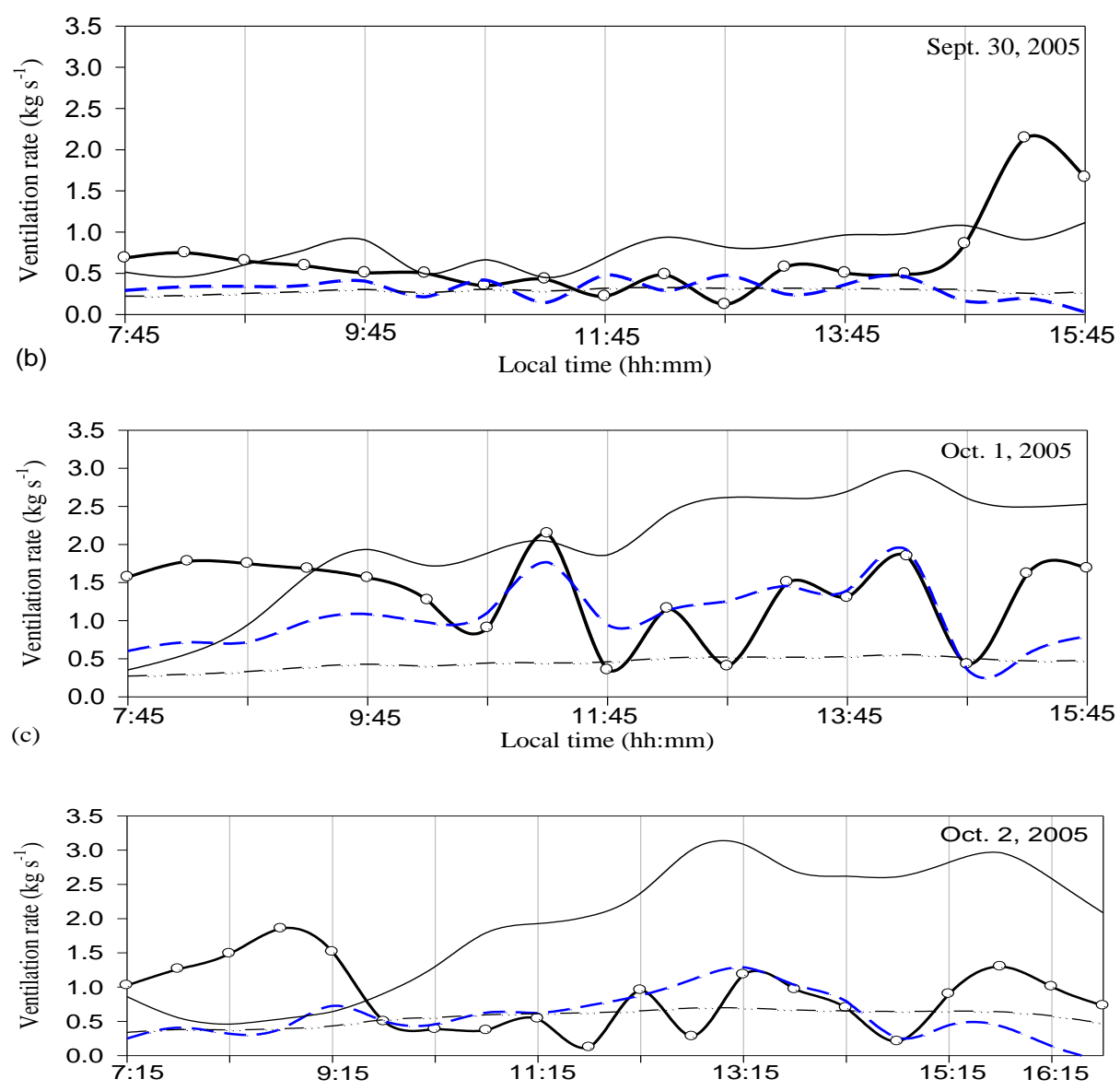

(d)

Local time (hh:mm)

$-\infty-$ Present model, - Eq. (1), $\mathrm{C}_{\mathrm{w}}=0.28,--\cdots$ Eq. (1), $\mathrm{C}_{\mathrm{w}}=0.006,---$ Eq. (2)

Fig. 7 Time courses of the natural ventilation rate $\left(\dot{m}_{\mathrm{a}}\right)$ estimated by using the present model; the fundamental heat balance (Eq. (2)); and the air dynamic model (Eq. (1)).

(i) Results of the three models (i.e. values of $\dot{m}_{\mathrm{a}}$ ) sometimes show reasonable agreement with each other (Fig. 7(b)) and sometimes show a large disagreement (Fig. 7(d)) depending on the environmental conditions inside and outside the greenhouse. 
(ii) The value of $\dot{m}_{\mathrm{a}}$ from Eq. (1) strongly depends on the value of $C_{\mathrm{w}}$ (Fig. 7(c) and (d)). Therefore, using this equation to estimate $\dot{m}_{\mathrm{a}}$ requires an in situ determination of the model parameters (i.e. $C_{\mathrm{w}}$ and $C_{\mathrm{d}}$ ) for the greenhouse under consideration.

(iii) Values of $\dot{m}_{\mathrm{a}}$ from Eq. (2) are zero or negative at low solar radiation levels (e.g. $S_{\mathrm{o}}$ $<190 \mathrm{~W} \mathrm{~m}^{-2}$ in Fig. 7(b) and (d). The negative values of $\dot{m}_{\mathrm{a}}$ are attributed to the fact that in the late afternoon the warm air in the greenhouse (i.e. $\Delta I>0$ ) is cooling down and the heat loss from the greenhouse is higher than the input solar energy to the greenhouse. In the present model, this problem was avoided by: (i) applying the heat balance in the unsteady state condition, (ii) dealing with the energy terms at the outer surface of the cover, and (iii) excluding the effect of thermal inertia of the greenhouse soil (i.e. source of error due to several uncertain parameters and assumptions usually used to estimate this term) by selecting the $c v$ over the floor surface.

\subsection{The Present Model and Experimental Measurements}

The rate of ventilation depends on the design configuration of the greenhouse and its ventilators and on the environmental conditions inside and outside the greenhouse (i.e. temperatures, humidity, wind speed and wind direction). Therefore, it was not possible to directly compare the results of the present model with those measured in different greenhouses under different conditions. The main purpose of this section is to present the results of the present model beside other measured results in a reasonable way to show the order of magnitude. The hourly average values of $\dot{m}_{\mathrm{a}}$ were calculated per unit area of vent opening from Sept. 29 to Oct. 2 and plotted in Fig. 8 against the wind speed $(V)$ outside the greenhouse.

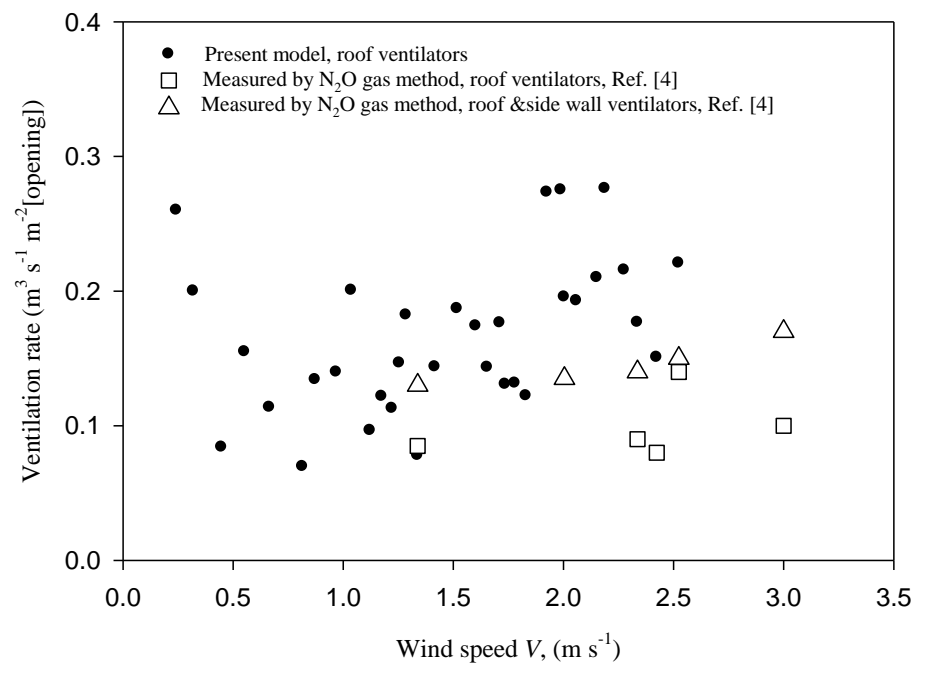

Fig. 8 Hourly average of the ventilation rate $\left(\dot{m}_{\mathrm{a}}\right)$, per unit area of vent opening, estimated by using the present model in comparison with the measured values of Ref. [4] as affected by the wind speed $(V)$ outside the greenhouse. 
In this figure, values of $\dot{m}_{\mathrm{a}}$ (per unit area of vent opening) measured by using the decay tracer $\mathrm{N}_{2} \mathrm{O}$ gas technique [4] are also presented. The measurements in Ref. [4] were carried out with opening two types of ventilators. It was roof and both roof and side walls ventilators in a multi-span greenhouse. At low speeds, the outside wind did not significantly affect either the estimated or the measured values of $\dot{m}_{\mathrm{a}}$ (Fig. 8). The measured values of $\dot{m}_{\mathrm{a}}$ of Ref. [4] are lower than those estimated using the present model because the greenhouse used in the present study was small $\left(A_{\mathrm{f}}=26 \mathrm{~m}^{2}\right)$, with two roof ventilators compared with the large greenhouse of Ref. [4] $\left(A_{\mathrm{f}}=882 \mathrm{~m}^{2}\right)$ that had one roof ventilator per span. Moreover, the two side wall ventilators in the large greenhouse of Ref. [4] did not significantly enhance the ventilation rate. Also the environmental conditions inside and outside the greenhouses are different between the present study and Ref. [4].

\subsection{Parameters Affecting the Ventilation Rate}

The main parameters affecting the natural ventilation rate are the outside wind speed $(V)$ and the temperature difference between inside and outside $\Delta T$. Hourly averages of the $\dot{m}_{\mathrm{a}}$ values were calculated, per unit area of floor, when the ventilators are opened during the four days. These values are plotted in Fig. 9 against the measured values of $V$ and in Fig. 10 against the measured values of $\Delta T$. Winds with speeds less than $2.5 \mathrm{~m} \mathrm{~s}^{-1}$ have no significant effect on the value of $\dot{m}_{\mathrm{a}}$ (Fig. 9); whereas value of $\dot{m}_{\mathrm{a}}$ estimated based on the greenhouse thermal balance is strongly affected by $\Delta T$ (Fig. 10) in an inverse relation. Eq.(2) shows the inverse relation between $\dot{m}_{\mathrm{a}}$ and $\Delta I$ as well as $\Delta T$.

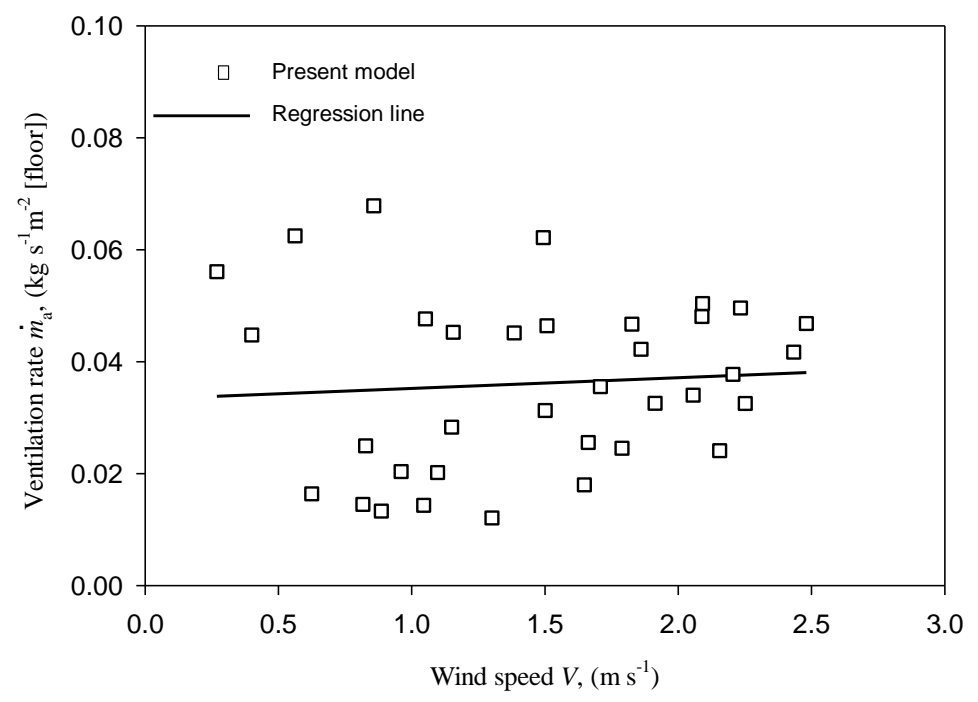

Fig. 9 Hourly average of the ventilation rate $\left(\dot{m}_{\mathrm{a}}\right)$ estimated for the unit area of floor by using the present model as affected by the wind speed $(V)$ outside the greenhouse. 
The regression line for the data in Fig. 10 is given by:

$\dot{m}_{\mathrm{a}}=0.0993-7.35 \times 10^{-3}(\Delta T)$

with value for the coefficient of determination $\left(r^{2}\right)$ of 0.77 .

This correlation can be used to estimate the required ventilation rate to maintain the air in a single-span greenhouse at a certain temperature stipulating that the outside wind speed is less than $2.5 \mathrm{~m} \mathrm{~s}^{-1}$. In summer seasons, $T_{\mathrm{di}}$ is always higher than $T_{\mathrm{do}}$, however, an outside air at a rate of about $0.1 \mathrm{~kg} \mathrm{~s}^{-1}$ is required (per unit area of greenhouse floor) for ventilating the greenhouse to maintain $T_{\mathrm{di}}$ equal to $T_{\mathrm{do}}$. On the other hand, closing the greenhouse openings ( $\left.\dot{m}_{\mathrm{a}}=0\right)$ increases $T_{\mathrm{di}}$ to about $13.5^{\circ} \mathrm{C}$ higher than $T_{\mathrm{do}}$.

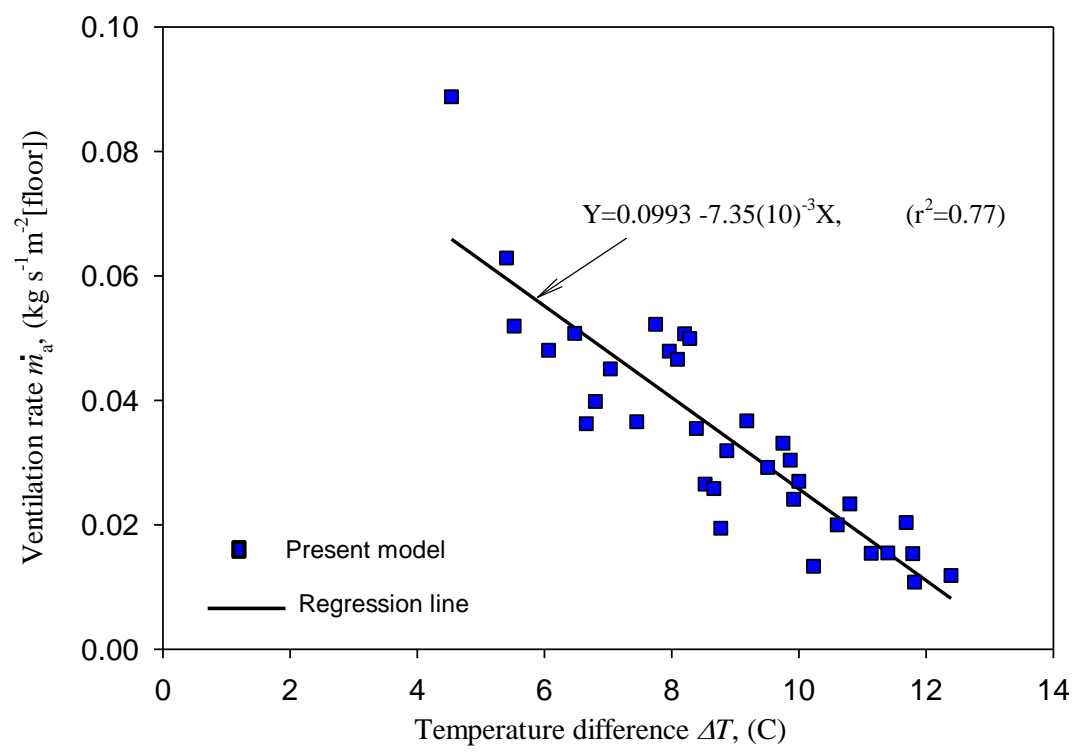

Fig. 10 Hourly average of the ventilation rate $\left(\dot{m}_{\mathrm{a}}\right)$ estimated for the unit area of floor by using the present model as affected by the difference between the inside and outside dry bulb temperature $(\Delta T)$.

\section{CONCLUSIONS}

The physical model presented in this study was based on a simple energy balance applied to a control volume containing the greenhouse. This model can be used to predict the natural ventilation rate of any greenhouse having: any transparent (in term of solar radiation) covering material, and any shape and size at any location. The model is capable of predicting the natural ventilation rate precisely because the uncertain parameters that cause errors were avoided. The simulated results using the present model showed a reasonable accordance with those measured and reported in the literature. The wind outside the greenhouse at a speed less than $2.5 \mathrm{~m} \mathrm{~s}^{-1}$ has no significant effect on the natural ventilation rate. The natural ventilation rate estimated 
based on the greenhouse thermal balance (e.g. the present model) strongly depends on the difference between the inside and outside air-dry bulb temperature $(\Delta T)$. Therefore, a linear correlation was provided $\left(r^{2}=0.77\right)$ that can be used to estimate the natural ventilation rate of greenhouses as a function of $\Delta T$ at low wind speed conditions.

\section{REFERENCES}

[1] Nederhoff, E. M., Van de Vooren, J. and Udink ten Cate, A. J., "A practical Tracer Gas Method to Determine Ventilation in Greenhouses", J. Agric. Eng. Res., 31(4), pp.309-319, 1985.

[2] Baptista, F. J., Bailey, B. J., Randall, J. M. and Meneses, J. F., "Greenhouse Ventilation Rate: Theory and Measurement with Tracer Gas Techniques", J. Agric. Engng. Res., 72, pp.363-374, 1999.

[3] Fernandez, J. E. and Bailey, B. J., "Measurement and Prediction of Greenhouse Ventilation Rates”, Agric. For. Meteorol., 58, pp.229-245, 1992.

[4] Parra, P. J., Baeza, E., Montero, J. I. and Bailey, B. J., "Natural Ventilation of Parral Greenhouses”, Boisystems Engineering, 87(3),pp. 355-366, 2004.

[5]Boulard, T. and Baille, A., "Modelling of Air Exchange Rate in a Greenhouse Equipped with Continuous Roof Vents”, J. Agric. Engng. Res., 61, pp.37-48, 1995.

[6] Boulard, T., Meneses, J. F., Mermier, M. and Papadakis, G., "The Mechanisms Involved in the Natural Ventilation of Greenhouses", Agric. For. Meteorol., 79, pp. 61-77, 1996.

[7] Teitel, M. and Tanny, J., "Natural Ventilation of Greenhouses: Experiments and Model”, Agric. For. Meteorol., 96, pp. 59-70, 1999.

[8] Mihara, Y., "Fundamental and Practice of Greenhouse Design (in Japanese)", Yokendo Inc., Tokyo, pp.160-169, 1983.

[9] Seginer, I., "Alternative Design Formulae for the Ventilation Rate of Greenhouses",

J. Agric. Engng. Res., 68, pp. 355-365, 1997.

[10] Arbel, A., Yekutieli, O. and Barak, M., "Performance of a Fog System for Cooling Greenhouses”, J. Agric. Engng. Res., 72, pp. 129-136, 1999.

[11] Boulard, T. and Baille, A., "Analysis of Thermal Performance of a Greenhouse as a Solar Collector", Energy in Agric., 6, pp.17-26, 1987.

[12] Kozai, T., "Direct Solar Light Transmission Into Single-Span Greenhouses", 
Agric. Meteorol., 18, pp. 327-338, 1977.

[13] Papadakis, G., Manolakos, D. and Kyritsis, S., "Solar Radiation Transmissivity of a Single-Span Greenhouse Through Measurements on Scale Models”, J. Agric.

Engng. Res., 71, pp. 331-338, 1998.

[14] Abdel-Ghany, A. M., Ishigami, Y., Goto, E. and Kozai, T., “A method for

Measuring Greenhouse Cover Temperature Using a Thermocouple”, Biosystems

Engineering, 95(1), pp. 99-109, 2006.

[15] Elsayed, M. M., Taha, I. S. and Sabbag, J. A., "Design of Solar Thermal Systems", $1^{\text {st }}$ ed. Jeddah, Saudi Arabia: Seientifc Publishing Centre, King Abdulaziz

University,1994.

[16] Abdel-Ghany, A.M., Kozai, T. and Chun, C., "Evaluation of Selected Greenhouse

Covers for Use in Regions with a Hot Climate”, Jpn. J. Trop. Agric., 45(4), pp.

242-250, 2001.

[17] Abdel-Ghany, A. M. and Kozai T., "Dynamic Modeling of the Environment in a Naturally Ventilated, Fog-Cooled Greenhouse”, Renewable Energy, 31, pp.15211539, 2006.

[18] Monteith, J. L. and Unsworth, M. H., "Principals of Environmental Physics", $2^{\text {nd }}$ ed., London, Arnold, 1990.

[19] Duffie, J. A. and Beckman, W. A., "Solar Engineering of Thermal Processes",

New York, John Wiley\& Sons Inc, 1991.

[20] Kozai, T., Sase, S. and Nara M., “A modeling Approach to Greenhouse

Ventilation Control”, Acta Hort., 106, pp.125-136, 1980.

\section{نموذج اتزان حراري لحساب التهوية الطبيعية في الصّوب الزراعية}

تقترض طرق الاتزان الحراري المستخدمة حالبا لحسـاب معدل التهويـة الطبيعيسة في الصـّوب الزراعيـة ( $\dot{m}_{a}$ أن الطاقة الداخلـة للصّّوبة هـي الإشـعاع الثمسي النافذ إلى

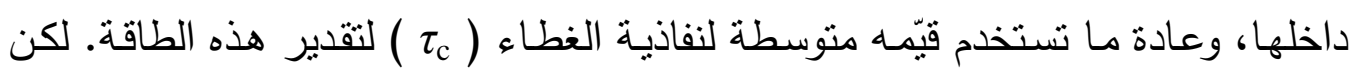

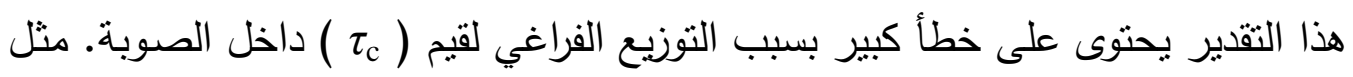


هذه الطرق تعطى أيضـا قيما سـالبة لـ ( الصباح والمساء). $\dot{m}_{a}$ الغرض من هذه الدراسة كان لاستتباط نموذج اتزان حراري مبسط يستخدم لحساب بدقة. في هذا النموذج ، كل أنماط الطاقة تمت معالجتها على السطح الخارجي لغطاء

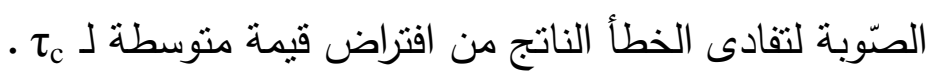
المتغيرات المناخية اللازمة لاستخدام هذا النموذج تم قياسها داخل وخارج صِّبة زجاجية مسـاحة ارضيتها 26 م2 في منطقة طوكيو باليابـان خـلال أربعـة أيسام مشمسـة مـن 29 سبتمبر إلى 2 أكتوبر 2005 م .تم تهوية الصوبة طبيعياً باستخدام فتحتي تهوية بالغطاء

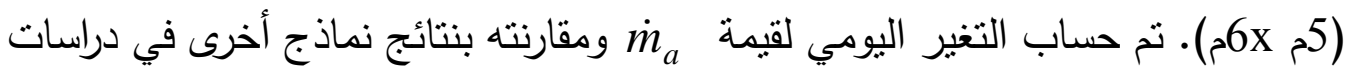

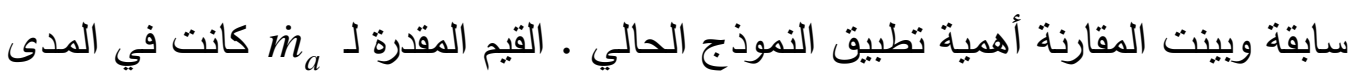
من 0.11 إلى 2.25 كجم/ث وهذه النتائج متطابقة مع تلك التي تم قياسها في دراسات عملية سابقة. أكدت النتائج أيضاً أن الرياح خارج الصوبة بسرعة أقل من 2.5 م/ث ليس لها تأثير

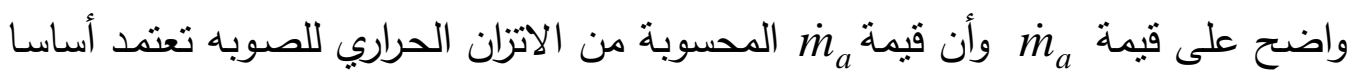

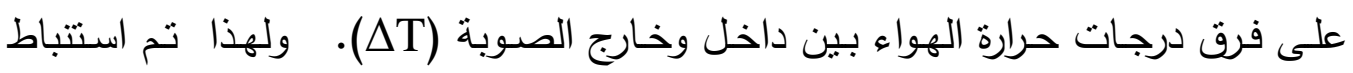
علاقة خطية بين

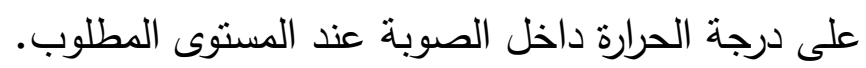

